RESEARCH ARTICLE

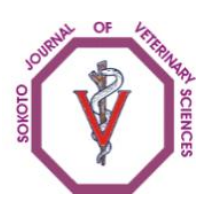

Sokoto Journal of Veterinary Sciences

(P-ISSN 1595-093X/ E-ISSN 2315-6201)

Bello /Sokoto Journal of Veterinary Sciences (2015) 13(3): 31-41.

http://dx.doi.org/10.4314/sokjvs.v13i3.6

\title{
Characteristics of commercial poultry and spatial distribution of metabolic and behavioural diseases in Oyo State, Nigeria
}

\author{
KO Bello ${ }^{1 *}$, LA Alebiosu' ${ }^{2}$, Lala $\mathrm{AO}^{1}$, Irekhore $\mathrm{OT}^{3}$ \& Oduguwa $\mathrm{OO}^{2}$ \\ 1. Institute of Food Security, Environmental Resources and Agricultural Research, \\ 2. College of Animal Science and Livestock Production; \\ 3. Agricultural Media Resources and Extension Centre, Federal University of Agriculture, Abeokuta \\ PMB 2240, Abeokuta, Ogun State, NIgeria
}

*Correspondence: Tel.: + 2348032204658, E-mail: kazeembello19@gmail.com

\begin{abstract}
This study was conducted to determine the characteristics, types and spread of poultry metabolic and behavioural diseases in Oyo State using a structured questionnaire spread across the 33 Local Government Areas of the state. One hundred commercial farms were randomly selected across the state but only seventy-eight responded. Data were collected on age of farm, number of stocks, types of poultry kept and types of poultry disease experienced and were analyzed using descriptive statistics. Coordinates of the farms were captured with the aid of Global Positioning System (GPS) and imported into Geographical Information System (GIS) to produce disease risk maps of the study area. Results revealed that $58.98 \%$ of the sampled poultry farms in Oyo State were established between 5 and 10 years ago and were mostly small scale commercial farms $(48.72 \%)$ with less than five thousand $(<5,000)$ birds. Only $3.84 \%$ of the farms possessed more than 120,000 birds, while $83.34 \%$ reared chicken, and $53.85 \%$ raised layers. The result also revealed that $89.74 \%$ of the farms experienced disease occurrence. Heat stress (23.08\%) and vent pecking (38.46\%) were the major metabolic and behavioural diseases, respectively experienced in Oyo State. The study concluded that majority of the commercial farms were small scale enterprises and layers constituted the highest proportion of chickens reared. Also, Oyo State had moderate to high potential for metabolic and behavioural diseases spread in 23 Local Government Areas while vent pecking and heat stress were the major diseases affecting most of the poultry commercial farms. Commercial poultry farms in Oyo State are enjoined to improve on their management techniques such as appropriate stocking density, good housing design and orientation, good feed and water management, effective structural and operation bio-security, proper hygiene and sanitation for better and efficient production targets.
\end{abstract}

Keywords: Behavioural disease, Commercial poultry, GIS, Metabolic disease, Oyo State

Received: 18-11-2014

Accepted: $12-10-2015$

\section{Introduction}

Nigerian Agricultural sector is identified with the provision of food and nutrition while poultry production is responsible for $19 \%$ of the meat supply (SAGTAP, 2012). The value of the commercial poultry industry in Nigeria is estimated at N80 billion $(\$ 600$ million) and is rated as the most industrialized component of the livestock Sub-sector. Over 25 million people are employed directly and indirectly in the commercial poultry industry. The subsector contributes over $25 \%$ of agricultural Gross Domestic Products (APPCT, 2012). Poultry products are highly nutritious and give good economic returns to man. Poultry meat is an important source of protein and is preferred to beef and pork, in terms of versatility, taste, ease of preparation, health consideration, nutrient composition and contribution to food security (Okunola \& Olofinsawe, 2007). However, disease has been identified as major challenge in 
poultry production as it prevents the industry from delivering on its targets (Akinyele et al., 2013). Disease is described as departure from health, and includes any condition that impairs normal body functions which results from a combination of direct as well as indirect causes that reduce resistance or predispose an animal to infection (Maseleno \& Hasan, 2012). It may be expressed as infectious, parasitic, behavioural and nutritional/metabolic (Ranchesca, 2011). Nutritional disturbances or diseases for example are a variety of diseases caused in different ways particularly due to nutrient insufficiency or imbalance. Diets may contain substances that inhibit/reduce nutrient absorption/utilisation, or there could be metabolic upset due to the interaction of dietary and environmental factors (Mézes et al., 1997).

In poultry, metabolic disorders include those conditions associated with increased metabolism, rapid growth rate or high egg production that result in the failure of a body system because of the increased work-load on the organ or system. Metabolic disorders, therefore, may result from an increased production, or deficiency of, or failure in the production, formation, or transport of hormone or secretory mechanisms which are related to management defects, nutritional imbalance and infection (Richard, 2005).

Behavioural diseases of poultry are behavioural patterns that are considered abnormal. They often lead to injury of either the abnormally behaving bird or other birds in the flock. Cannibalism, vent and aggressive pecking are some of the behavioral diseases in poultry. Whichever form poultry disease is presented, it poses serious challenges to farmers and birds and can cause significant production losses (Maseleno \& Hasan, 2012) as a result of increased mortality, poor feed conversion, reduced productivity, poor product quality and low returns on investment. Disease is usually not localized. It could occur across a particular location, country, and or region even across widest area depending on risk factors.

Spatial epidemiology is the description and analysis of geographic variations in disease with respect to demographic, environmental, behavioral, socioeconomic, genetic, and infectious risk factors. Mapping and modeling methods have been used to study the spatial distribution and spread of diseases and are increasingly utilized in modern day epidemiology (Elliot \& Wartenberg, 2004). Meanwhile, metabolic and behavioural diseases may be influenced by environment, socio-economic and genetic factors. The interactions partly between socio-economics, genetics and environment in various locations, coordinates and/or countries among other factors determine variations in disease risk and therefore make disease transmission essentially a spatial process (Lambin et al., 2010).

Remote sensing and Geographical Information Systems (GIS) have emerged as a computer based tool for any discipline which handles data that can be connected with locations, countries and regions for analysis (Kitron, 2000), including information on specific maps and attributes (Kitron, 1998). However, in Nigeria, most studies on poultry diseases are not spatially-explicit valuable tools for understanding the dynamics and required interventions.

Most studies that assessed the impact of poultry diseases in Nigeria have ignored the broader picture of the livelihood effects (Akpabio et al., 2007; Obayelu, 2007; You \& Xinshen, 2007) and spread. This limits the evidence base of discussions that could lead to the development of appropriate policy and development plan for active disease surveillance in poultry production systems. General household surveys conducted by National Bureau of Statistics (NBS) between 1995 and 2005 show that children (0 - 14 years) constitute a high percentage (about 37\%) of the household population in Nigeria (NBS, 2007). This figure is an indication of the important role of poultry to the nation as children need food with high animal protein content which eggs and chicken readily provide. Therefore, poultry disease outbreaks could be a great threat to household food security in a populous state like Oyo with over 6 million people (NBS, 2007) and the teeming population in Nigeria.

This study was therefore necessitated by the need to support increasing efforts at eradicating diseases and to serve as early warning system to players and would-be investors in the poultry industry. It will also provide facts that will aid Government efforts on poultry transformation and action plan for job creation and food security since there is a dearth of information on spatial distribution on metabolic and behavioural diseases in Oyo State.

\section{Materials and methods}

Study area

The study was carried out in Oyo State. Oyo State is one of the 36 States of the Federal Republic of Nigeria with headquarters in Ibadan. It has a land area of 27,249 square kilometers (Fajuyigbe et al., 2007). The state is bounded in the north by Kwara State, in the south by Ogun State, in the east by Osun State, in the west partly by Ogun 


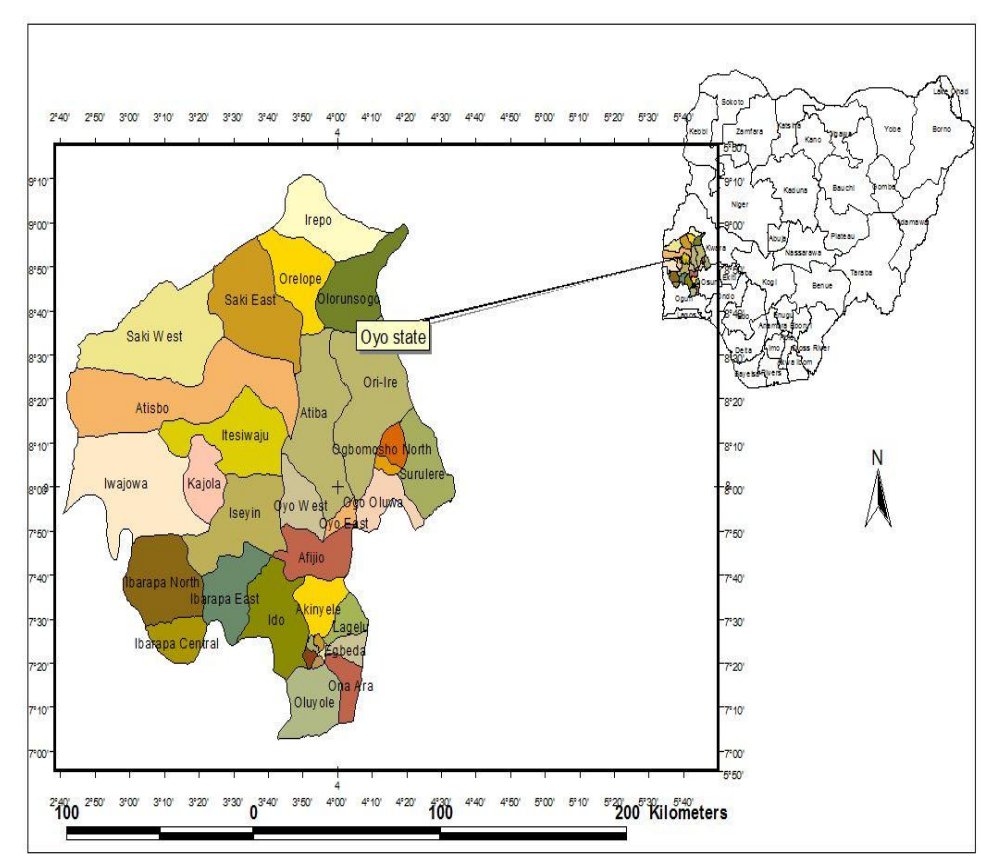

Figure 1: Map of Oyo State showing 33 Local Government Areas Source: Cartographic Laboratory, IFSERAR, FUNAAB

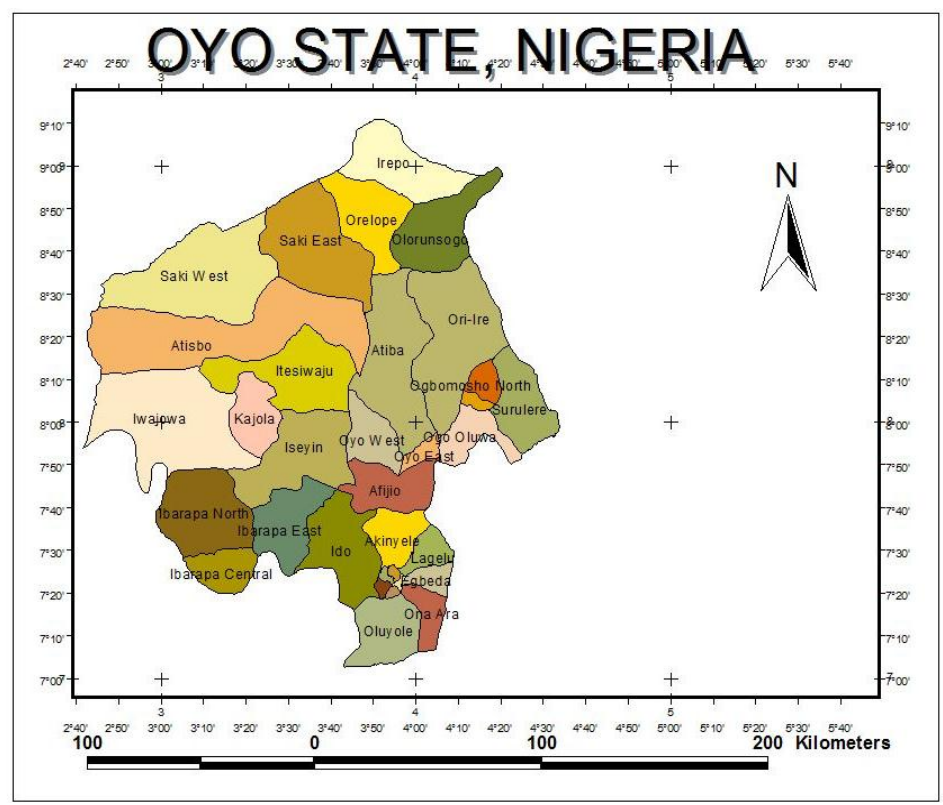

Figure 2: Map of Oyo State showing 33 Local Government Areas Source: Cartographic Laboratory, IFSERAR, FUNAAB
State and partly by Republic of Benin (Figure 1). It is located on latitude $8^{\circ} 00^{\prime} \mathrm{N}$ and longitude $4^{\circ} 00^{\prime} \mathrm{E}$ (Google Earth, 2015). The vegetation pattern is that of rain forest in the South and guinea savannah in the North.

There are five geographical distributions of people of Oyo State namely; Ibadan, Ogbomoso, Oke-Ogun, Oyo and Ibarapa. Some of the important cities and towns in the state are Ibadan, Oyo, Ogbomoso, Iseyin, Saki, Igboho, Lalupon, Kisi, Okeho, Fiditi, llora, Eruwa, Igbo-ora, etc. (Figure 2).

\section{Data collection procedure}

The data used for this study were obtained from both primary and secondary sources. Primary data were collected through survey involving the use of structured questionnaire to obtain information on commercial poultry farms and one-on-one interview of poultry farmers. The survey covered the five geographical areas of the people of Oyo State (Ibadans, Oyos, Ogbomosos, Okeoguns and Ibarapas). A purposive random sampling technique was used to select 100 commercial poultry farms in the study area comprising of 20 farms per geographical area. One hundred (100) copies of the questionnaire were given out but only seventy eight (78) were retrieved. Data were collected on farm characteristics such as age of poultry, membership of poultry association, poultry type, flock size, disease occurrence and types of metabolic and behavioural diseases affecting the birds. Global Positioning System (GPS) was used to record the coordinate of each farm visited. 


\section{Statistical analysis}

Data collected were analyzed using descriptive statistics such as percentage and frequency of distribution as contained in SPSS (2002). Coordinates of the farms were captured with GPS and imported into Geographical Information System (GIS) software (ArcGIS 9.3) to produce disease risk maps of the study area.

\section{Results}

Table 1 shows characteristic of commercial poultry farms in Oyo State. About one-third (34.62\%) of the farms in the study area were between 5 and 10 years of age. Poultry farms that were established less than 5 years represented $24.36 \%$ of the sampled farms while those between 11 and 15 years of age constituted $21.80 \%$. The result also revealed that poultry farms of more than 20 years in existence represented $10.25 \%$ of the commercial poultry farms in the study area. Furthermore, farms established less than 10 years constituted $58.98 \%$ of the farms population in Oyo state.

Number of flocks varied from farm to farm in this study. Almost half (48.72\%) of the respondents had a flock size of less than 5000 birds. This was closely followed by farms with flock size of between 5000 and 50000 birds (42.31\%) while only $5.13 \%$ of the respondents had between 50001 and 120000 birds. Only $3.84 \%$ of the poultry farms possessed more than 120,000 birds. Majority (85.90\%) of the respondents were members of Poultry Association of Nigeria, Oyo State (PANOY). The result of the species of poultry reared by commercial poultry farms in Oyo State is shown in table 2. Chicken was the major (83.34\%) poultry species reared in the State. Some farms reared more than one poultry species. The result revealed that $11.54 \%$ of the respondents reared both chicken and turkey while $1.28 \%$ reared chicken and duck. The same value (1.28\%) was recorded for farmers that reared chicken and ostrich, chicken and guinea fowl and a combination of chicken, turkey, guinea fowl and quail. A little over half $(53.85 \%)$ of the commercial poultry farms in Oyo State reared layers while $5.13 \%$ reared Parent Stock (PS). It was also observed that some farms raised more than one type of chickens. About onetenth $(10.26 \%)$ of the respondents reared broilers, layers and cockerels, $11.54 \%$ reared broilers and layers, while $5.13 \%$ reared layers and pullet chicks only. The study also revealed that $1.28 \%$ of the poultry farms in Oyo State reared commercial layers and PS, 7.69\% reared layers (commercial) and cockerels while $3.84 \%$ of the population reared combination of more than three poultry types (Table 2). Table 3 shows disease occurrence among commercial poultry farms in Oyo State. The result

Table 1: Characteristic of Commercial Poultry Farms in Oyo State

\begin{tabular}{lll}
\hline Measurement & Frequency & Percentage (\%) \\
Age of Poultry Farm & & 24.36 \\
\hline$<5$ years & 19 & 34.62 \\
$5-10$ years & 27 & 21.80 \\
$11-15$ years & 17 & 8.97 \\
$16-20$ Years & 7 & 10.25 \\
$>20$ years & 8 & 100.00 \\
Total & 78 & \\
Flock size of Commercial Poultry in Oyo State & 48.72 \\
\hline$<5000$ & 38 & 42.31 \\
$5000-50000$ & 33 & 5.13 \\
$50001-120000$ & 4 & 3.84 \\
$>120000$ & 3 & 100.00 \\
Total & $\mathbf{7 8}$ & \\
Membership of Poultry Association of Nigeria, Oyo State Chapter (PANOY) & 85.90 \\
\hline Yes & 67 & 14.10 \\
No & 11 & 100.00 \\
Total & $\mathbf{7 8}$ & \\
\hline
\end{tabular}


Table 2: Species of poultry and chickens reared in commercial poultry farms in Oyo State

\begin{tabular}{|c|c|c|}
\hline Types of poultry kept & Frequency & Percentage \\
\hline Chicken & 65 & 83.34 \\
\hline Duck & 0 & 0 \\
\hline Turkey & 0 & 0 \\
\hline Geese & 0 & 0 \\
\hline Pigeon & 0 & 0 \\
\hline Guinea Fowl & 0 & 0 \\
\hline Ostrich & 0 & 0 \\
\hline Quail & 0 & 0 \\
\hline Chicken/Turkey & 9 & 11.54 \\
\hline Chicken /Duck & 1 & 1.28 \\
\hline Chicken /Ostrich & 1 & 1.28 \\
\hline Chicken/Guinea Fowl & 1 & 1.28 \\
\hline Chicken/Turkey/Guinea fowl/ Quail & 1 & 1.28 \\
\hline Total & 78 & 100.00 \\
\hline \multicolumn{3}{|l|}{ Chicken kept } \\
\hline Broiler & 0 & 0.00 \\
\hline Layers & 42 & 53.85 \\
\hline Cockerel & 0 & 0.00 \\
\hline Pullet chicks & 0 & 0.00 \\
\hline Parent Stock & 4 & 5.13 \\
\hline Grand Parent Stock & 0 & 0.00 \\
\hline Broiler/Layer & 9 & 11.54 \\
\hline Layer/Pullet chick & 4 & 5.13 \\
\hline Layers/Parent Stock & 1 & 1.28 \\
\hline Layer/Cockerel & 6 & 7.69 \\
\hline Broiler/layer/cockerel & 8 & 10.26 \\
\hline Layer/cockerel/Pullet & 1 & 1.28 \\
\hline Broiler/Layer/Cockerel/Pullet & 2 & 2.56 \\
\hline Broiler/Layer/Cockerel/Parent Stock & 1 & 1.28 \\
\hline Total & 78 & 100.00 \\
\hline
\end{tabular}

Table 3: Disease occurrence among commercial poultry farms in Oyo State

\begin{tabular}{lcc}
\hline Disease occurrence & Frequency & Percentage \\
\hline Yes & 70 & 89.74 \\
No & 8 & 10.26 \\
Total & 78 & 100.00 \\
Frequency of occurrence & & \\
Very high & 2 & 2.56 \\
High & 10 & 12.82 \\
Moderate & 31 & 39.74 \\
Low & 23 & 29.49 \\
Very low & 12 & 15.39 \\
Total & 78 & 100.00 \\
\hline
\end{tabular}


Table 4: Types of Metabolic/Nutritional diseases affecting commercial poultry farms in Oyo States

\begin{tabular}{llc}
\hline Metabolic/nutritional disease type & Frequency & Percentage \\
\hline Cage Layer Fatigue & 7 & 8.97 \\
Heat Stress & 18 & 23.08 \\
Vitamin E & 1 & 1.28 \\
Vitamin D & 2 & 2.56 \\
Slipped Tendon & 0 & 0.00 \\
Fatty liver & 0 & 0.00 \\
Dehydration/Fatty liver & 1 & 1.28 \\
Heat Stress / Fatty liver & 3 & 3.85 \\
Heat Stress /Vitamin D & 1 & 1.28 \\
Cage Layer Fatigue / Heat Stress & 16 & 20.51 \\
Cage Layer Fatigue/Heat Stress/Vitamin D & 3 & 3.85 \\
Cage Layer Fatigue/Heat Stress/ Fatty liver & 2 & 2.56 \\
Heat Stress /Vitamin D / Fatty liver & 1 & 1.28 \\
Cage Layer Fatigue/Heat Stress/Slipped tendon/Fatty liver & 1 & 1.28 \\
Cage Layer Fatigue/Heat Stress/Dehydration/Fatty liver & 1 & 1.28 \\
None & 21 & 26.92 \\
Total & 78 & 100.00 \\
\hline
\end{tabular}

Table 5: Types of behavioural disease affecting poultry farms in Oyo State

\begin{tabular}{lcc}
\hline Behavioural Disease Type & Frequency & Percentage \\
\hline Vent pecking & 30 & 58.46 \\
Aggressive pecking & 4 & 0.00 \\
Toe pecking & 0 & 7.70 \\
Feather pecking & 6 & 0.00 \\
Cannibalism & 0 & 51.29 \\
\hline One behavioural disease type sub group & 15.4 \\
Feather pecking/Vent pecking & 12 & 2.56 \\
Cannibalism/Vent pecking & 2 & 1.28 \\
Toe pecking/Vent pecking & 1 & 1.28 \\
Cannibalism/Aggressive pecking & 1 & 2.56 \\
Aggressive pecking/Vent pecking & 2 & 2.56 \\
Aggressive pecking/Feather pecking & 2 & 25.64 \\
\hline Two behavioural disease type sub group & 20 & 2.56 \\
Cannibalism/Feather pecking/Vent pecking & 2 & 1.28 \\
Cannibalism/Aggressive pecking/Vent pecking & 1 & 2.56 \\
Cannibalism/Aggressive pecking/Feather pecking/Vent pecking & & 1.28 \\
Cannibalism/Aggressive pecking/Toe pecking/ Feather & 2 & 7.70 \\
pecking/Vent pecking & & 15.40 \\
\hline More than two behavioural disease type sub group & 1 & 100.00 \\
\hline None & 6 & 12 \\
\hline
\end{tabular}


revealed that majority $(89.74 \%)$ of the poultry farms in the State had experience of disease occurrence on their farms. Frequency of disease occurrence among commercial poultry farms in Oyo State is also shown in table 3. Less than half $(39.74 \%)$ of the respondents reported that they have disease occurrence at moderate rate while about one third (29.49\%) had the occurrence at low rate. The result indicated that $15.39 \%$ of the farms surveyed reported very low rate of disease occurrence while $12.82 \%$ of the respondents experience high rate of disease occurrence. Only $2.56 \%$ of the farms recorded very high rate of disease occurrence in the State. Metabolic/nutritional diseases affecting commercial poultry farms in Oyo State are shown in table 4. Heat stress was the singular major metabolic/nutritional disease confronting the farms as reported by $23.08 \%$ of the respondents. The result revealed that cage layer fatigue was a singular metabolic/nutritional disease that affected $8.97 \%$ of the sampled farms. This was followed by vitamin $D$ and $E$ deficiencies representing $2.56 \%$ and $1.28 \%$, respectively. The result revealed that some farms (6.41\%) were faced with more than one type of metabolic/nutritional disease while $30.67 \%$ of the respondents reported a combination of three or more metabolic/nutritional disease occurrence (Table 4).

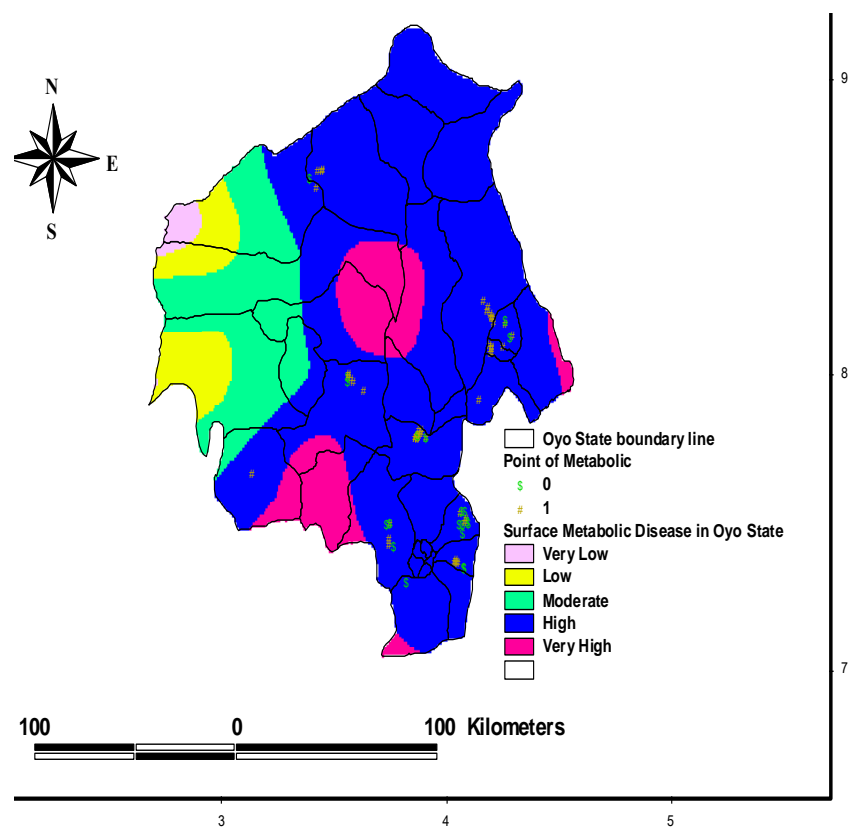

Figure 3: Spatial Distribution of Metabolic Diseases in Oyo State
Types of behavioural diseases affecting commercial poultry farms in Oyo State are shown in table 5. Vent pecking was observed to be the most common behavioural disease and it was reported by $38.46 \%$ of the respondents. The study revealed that $7.7 \%$ of the farms were challenged with feather pecking while $5.53 \%$ reported aggressive pecking. The study also showed that $25.64 \%$ of the respondent farms experienced two behavioural diseases at a time while $\mathbf{7 . 7 0 \%}$ experienced three or more behavioural diseases at a time. However, $15.40 \%$ of the farms had never experienced any behavioural disease.

\section{Spatial distribution of metabolic diseases in Oyo}

State

Figure 3 shows the spatial distribution of metabolic/nutritional diseases in Oyo State. The result revealed that Oyo State has high potential for metabolic/nutritional diseases. These diseases covered major parts (30 Local Government Areas) of the state and land area of about 13,498sq.km. Highest potential of metabolic disease was recorded in some parts of ten (10) LGAs with a land area of about 7,423sq.km which were scattered at extreme east, extreme south, central and southwest regions of the state. Majority of the areas within the northwest and southwest regions of Oyo State could be assumed to have a moderate to very

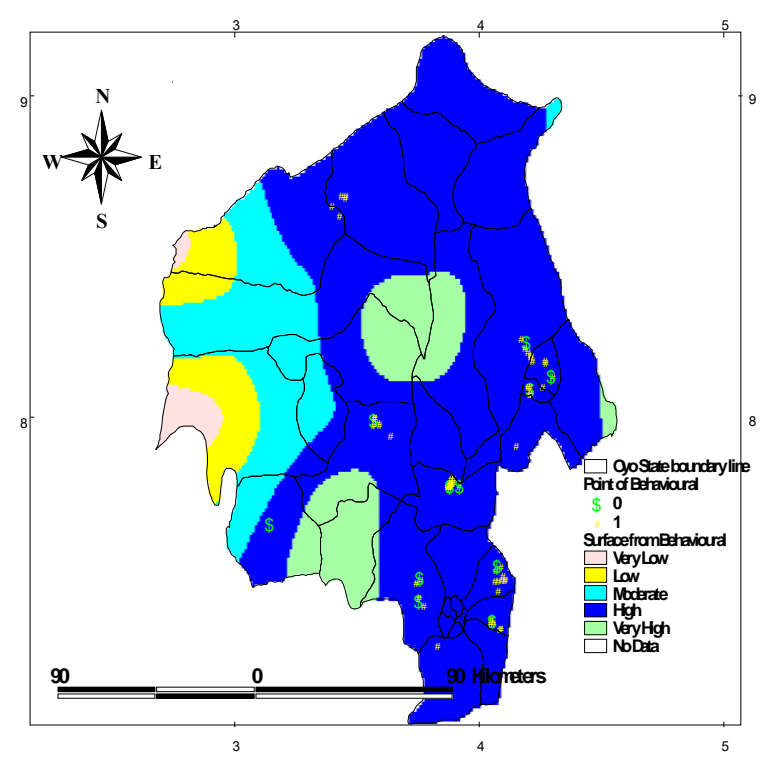

Figure 4: Spatial distribution of Behavioural diseases in Oyo State 
low potential for metabolic disease occurrence. Spatial distribution of behavioural diseases in Oyo State

Spatial distribution of behavioural diseases in Oyo State is as shown in Figure 4. The result revealed that Oyo State had high potential for behavioural disease. Highest potential was recorded in some parts of ten (10) LGAs and covered a land area of about $6342 \mathrm{sq} . \mathrm{km}$ which were scattered over the extreme east, extreme south, central and northeast regions of the state. Majority of the areas within the northwest and southwest regions of Oyo State could be assumed to have moderate to very low potential of behavioural disease occurrence.

\section{Discussion}

The result on age of poultry of commercial poultry farms in Oyo State was in accordance with the findings of Bamiro et al. (2006) who reported that farming experience of the bulk (about 68\%) of poultry farmers in Oyo State spans between 1 and 10 years, while about $58 \%$ of their counterparts in Ogun State have farming experience that spans between 1 and 10 years. It was also a reflection of the fast rate of expansion and development of the poultry business in the last two decades as the Nigerian poultry industry and in the developing world has been described as growing venture (FAO, 2011).

The number and size of flocks in the study area showed that most of the farms were operating at small scale level with less than five thousand $(<5,000)$ birds. This could be a reflection of the fact that commercial poultry production is capital intensive with huge financial outlay required for large and industrialized scale production. The low capital base of most of the farmers could be responsible for the small scale production size. This finding agrees with the reports of Timothy et al. (2011) and Akinyele et al. (2013) that poultry is an important instrument for alleviating problems associated with poverty, food insecurity and malnutrition in Nigeria thus it attracts the interest of low resource farmers.

The result of the species of poultry reared by commercial poultry farms in Oyo State revealed that the poultry industry in Oyo State was dominated by chicken rearing. This finding was corroborated by Maseleno \& Hasan (2012) which stated that the poultry industry is dominated by the chicken companies. Udoh \& Etim (2007) also reported that poultry is the most commonly kept livestock with over $70 \%$ of livestock farmers are reported to be keeping chickens.

The fact that majority of the poultry farms in Oyo State keep layers was not unexpected as Oyeyinka et al. (2011) opined that, keeping layers is more profitable to the farmers than keeping broilers, cockerels, pullet and others in Oyo State. The opinion that eggs have no substitute, as a viable product which may be sold locally or in other areas could be responsible for the edge that layer have over other species. Chicken is taken mostly during festive periods. However, while layers produce the egg which has no substitute in terms of shelf life, longevity in raw form and is the cheapest protein source (Akinyele et al., 2013).

Majority (85.90\%) of the respondents were members of Poultry Association of Nigeria, Oyo State (PANOY) as shown in table 3. This could be as a result of government intervention in poultry production and the potential benefit to members. It could also be attributed to the place of poultry business as a mean of livelihood since only registered members could benefit from government interventions in case of challenges. As poultry is a fast developing and highly diversified industry, farmers need to share knowledge, information and experience through association such as Poultry Association of Nigeria, Oyo State (PANOY) in particular and Poultry Association of Nigeria (PAN) in general. The report of Timothy et al. (2011) gives credence to these findings.

Likewise, majority (89.74\%) of the poultry farms in the study area had experience of disease occurrence on their farms. This could be due to the type of production system (intensive) adopted. Keeping poultry under intensive system could be a pointer to good management and record keeping. Extensive management system cares less about the birds and less recognition on morbidity. Membership of PANOY could have contributed to the ability to keep adequate records and monitor disease occurrence. Frequency of disease occurrence that was reported to be moderate in most of the farms in the study area could be due to early diagnosis and treatment of sick birds by virtue of the intensive management system and experience acquired as members of PAN and PANOY.

Poultry farms in Oyo State recorded mortalities due to heat stress. This finding was in accordance with that of Bianca (1976), Ubosi \& Gandu (1995), 
Piccione \& Caola (2002) who in their various reports indicated heat stress as a major limiting factor to poultry productivity in hot-humid zones of the world. Ayo et al. (2005) also affirmed that the adverse effects of heat stress on pullets is pronounced during the hot-dry season when there are marked fluctuations in ambient temperature (AT) and relative humidity (RH). According to Freeman (1988) and Balnave (1998), prolong high AT during the day causes panting in pullets for several hours in order to dissipate excessive body heat through evaporative cooling. Sinkalu et al. (2006) also supported the opinion that the presence of high $\mathrm{RH}$ in the poultry houses during the hot-dry season makes evaporative cooling practically impossible. This justifies the results obtained since Oyo State is located within the hot-humid zone.

Spatial distribution of metabolic disease in Oyo State could be as a result of the system of agricultural operation of the people within the area who engage more in crop farming, ruminant production and indigenous poultry rearing. Areas with very low potential could be due to the proximity to Benin Republic. Sixty four percent (64\%) of the workforce in Benin is engaged in agriculture, forestry, or fishing. The largest shares are subsistence farmers. The principal food crops are beans, cassava, corn, millet, sorghum, and yams. Cash crops, produced mainly in the south, include cotton, palm kernels, peanuts, and sugarcane. The herding of cattle, sheep, and goats predominates in the grasslands of the north. The illustration here could be responsible for the result obtained.

The result showed that feather and vent pecking were the two major behavioural diseases experienced simultaneously in Oyo State. However, $7.70 \%$ of the farms had three behavioural diseases together at a time. Cannibalism, aggressive, vent and feather pecking were observed to be common. It was interesting to observe that $15.39 \%$ of the farms in the study area reported no behavioural disease.

Vent pecking as a mode of cannibalism had been reported to be one of the major causes of death in commercial laying hens (Appleby \& Hogarthm, 1991; Glatz, 2000). This finding was also supported by Abrahamsson \& Tauson (1998) who reported mortality rates of $4-20 \%$ due to cannibalism. Also, Van Krimpen et al. (2005) posited mortalities up to $30 \%$ as a result of cannibalism in laying hens. Behavioural disease could result through management practices such as improper feeding and high stocking density. Where facilities are over stretched and the animals are stocked beyond the optimum population, vices such as pecking fighting are not uncommon (Mtileni et al., 2007)

Majority of the areas within the northwest and southwest regions of Oyo State could be assumed to have moderate to very low potential of behavioural disease occurrence. This distribution could be as a result of high concentration of poultry farms and types of chicken kept. Some of the farms located in Oyo central and south-eastern part of the state had very high incidence of behavioural disease. This result could be due to the intensive production system practiced as this system exposed them to higher level of behavioural disease where resourced are over stretched.

The study concluded that most of the commercial poultry farms in Oyo State were established less than ten (10) years ago. Majority of the farms were small scale enterprises. Chicken was the major poultry reared in all the farms in the state with layers constituting the highest proportion of chickens. The study also concluded that Oyo State had moderate to high potential for metabolic and behavioural disease spread while vent pecking and heat stress were the major diseases affecting most of the poultry farms in the state. Commercial poultry farms in Oyo State are enjoined to improve on their management techniques such as appropriate stocking density, good housing design and orientation, good feed and water management, effective structural and operation bio-security, proper hygiene and sanitation for better and efficient production targets. 


\section{References}

Abrahamsson P \& Tauson R (1998). Performance and egg quality of laying hens in an aviary system. Journal of Applied Poultry Research 7(3): 225-232.

Action Plan for Poultry Commodity Transformation in Nigeria (APPCT) (2012). Poultry transformation Report. Federal Ministry of Agriculture and Rural Development, Abuja, Nigeria. Pp 1-30.

Akinyele AJ, Bello KO, Oyedepo JA, Oduguwa OO \& Fanimo AO (2013). Characteristics and opportunities of indigenous poultry in Ogun State, Nigeria: A case study of Yewa North Local Government Area. Nigerian Journal of Poultry Science, 9:149-159.

Akpabio IA, Okon DP, Angba AO \& Aboh CL (2007). Avian influenza scare and poultry egg production in Uyo Urban, Nigeria. International Journal of Poultry Science, 6 (4): $298-301$.

Appleby MC \& Hogarthm GS (1991). Welfare of laying hens in cages and alternative systems: Environmental, physical and behavioural aspects. World's Poultry Science Journal. 47(2): 109-128.

Ayo JO, Minka NS \& Fayomi A (2005). Effects of ascorbic acid on rectal temperature of pullets transported by road during the hotdry season in Northern Nigeria. Proc. Xth Annual Conference of Animal Science Association of Nigeria. Tropical Journal of Animal Science, 8:43-48.

Balnave D (1998). Increased utilization of sensible heat loss mechanisms in high temperature, high humidity conditions. World's Poultry Science Journal. 54(1): 69-72.

Bamiro OM, Phillip DO \& Momoh SO (2006). Vertical integration and production efficiency in poultry (egg) industry in Ogun and Oyo States, Nigeria. International Journal of Poultry Science, 2(12): 1164-1171.

Bianca W (1976). The significance of meteorology in animal production. International Journal Biometeorology, 20(2): 139- 156.

Elliott P \& Wartenberg D (2004). Spatial epidemiology: current approaches and future challenges. Environmental Health Perspectives, 112(9): 998-1006.

Fajuyigbe O, Balogun VF \& Obembe OM (2007). Web-based geographical information system (GIS) for tourism in Oyo State,
Nigeria. Information Technology Journal, 6:613-622.

Food and Agricultural Organization of the United Nat ions (FAO), (2011). Feeding the Future: World Livestock 2011. Livestock in Food Security. FAO of the United Nations, Rome. Pp 130.

Freeman BM (1988). The domestic fowl in biomedical research: Physiological effects of the environment. World's Poultry Science Journal, 44(1): 41-60.

Google Earth (2015). New Google Earth Imagery. www.gearthblog.com/.../2015/.../newgoogle-earth-imagery-june-8th-20, retrieived 08-06-2015.

Glatz PC (2000). Beak trimming methods. Review. Asian Australian Journal of Animal Science, 13(1): 1619-1637.

Kitron $U$ (1998). Landscape ecology and epidemiology of vector-borne diseases: tools for spatial analysis. Journal of Medical Entomology, 35(4): 435-45.

Kitron U (2000). Risk maps: transmission and burden of vector-borne diseases. Parasitology Today, 16(8): 324-335.

Lambin EF, Annelise T, Sophie OV, Catherine L \& Valérie S (2010). Pathogenic landscapes: interactions between land, people, disease vectors, and their animal hosts. International Journal of Health Geographics. 9:54. doi: 10.1186/1476-072X-9-54.

Maseleno A \& Hasan MMD (2012). Poultry diseases warning system using dempster-shafer theory and web mapping. International Journal of Advanced Research in Artificial Intelligence, 1(3): 44-48.

Mézes M, Surai $P$, Sályi G, Speake BK, Gaál T \& Maldjian A (1997). Nutritional metabolic diseases of poultry and disorders of the biological antioxidant defence system. Acta Veterinaria Hungarica 45(3): 349-60.

Mtileni BJ, Nephawe KA, Nesamvuni AE \& Benyi K (2007). The influence of stocking density on body weight, egg weight, and feed intake of adult broiler breeders hens. Poultry Science 86(6): 1615-1619.

National Bureau of Statistics, (NBS) (2007). General Household Survey Report, 1995 - 2005. Federal Republic of Nigeria. March 2007. Pp 194. 
Obayelu AE (2007). Socio-economic analysis of the impacts of avian influenza epidemic on households poultry consumption and poultry industry in Nigeria: Empirical investigation of Kwara State. Livestock Research for Rural Development, 19(1): 4.

Okunola JO \& Olofinsawe A (2007). Effect of extension activities on poultry production in Ondo State, South Western Nigeria. Agricultural Journal, 2(5): 559-563.

Oyeyinka RA, Raheem WK, Ayanda IF \& Abiona BG (2011). Poultry farmers' awareness and knowledge of improved production practices in Afijio local government area, Oyo State, Nigeria. Journal of Agricultural Research and Development, 1(1):1-8.

Piccione G \& Caola G (2002). Biological rhythm in livestock. Journal of Veterinary Science, 3(3): 145-157.

Ranchesca P (2011). Poultry Diseases: Causes, Symptoms and Treatment. http:// ezine articles, retrieved 24-06-2015

Richard JJ (2005). Production and growth related disorders and other metabolic diseases of poultry - A review. The Veterinary Journal, 169 (3): 350-369.

Sheep and goats transformation action plan (SAGTAP), (2012). Implementation Plan for Livestock Transformation Action Plan. Federal Ministry of Agriculture and Rural Development, Abuja, Nigeria. Pp 20.

Sinkalu VO, Ayo JO \& Dzenda T (2006). Effects of vitamin $A$ on diurnal variations in rectal temperature of Black Harco pullets during the hot-dry season. In: Proceeding of $11^{\text {th }}$,
Annual Conference of Animal Science Association of Nigeria at Institute of Agricultural Research and Training (IAR\&T), Ibadan, Oyo State. Pp 16-19.

Statistical Package for Social Science (SPSS), (2002). SPSS.12 for Windows. SPSS Inc Chicago. Illinois. USA.

Timothy UO, Olubukola A \& Garba AM (2011). ProPoor HPAl risk reduction strategies in Nigeria-background paper. International Food Policy Research Institute (IFPRI). Africa/Indonesia Region Report No.5. Pp 115.

Ubosi CO \& Gandu FD (1995). Effect of dietary treatments of ascorbic acid on productive performance and egg quality of caged laying chickens in the semi-arid zone of Nigeria. Discovery and Innovation, 7(1): 77-82.

Udoh EJ \& Etim NA (2007). Application of stochastic production frontier in the estimation of technical efficiency of cassava based farms in Akwa Ibom State, Nigeria. Agricultural Journal, 2(6):731-735.

Van Krimpen MM, Kwakkel RP, Reuvekamp BFJ, Van der Peet-Schwering CMC, Den Hartog LA \& Verstegen, MWP (2005). Impact of feeding management on feather pecking in laying hens. World's Poultry Science Journal, 61(4): 663-685.

You L \& Xinshen D (2007). Assessing the potential impact of avian influenza on poultry in West Africa: A spatial equilibrium analysis. Journal of Agricultural Economics, 58(2): $340-367$. 